\title{
Systems Coaching, Models of Typology, and Emergence
}

\author{
Vicky Jo Varner \\ Los Angeles, USA
}

\begin{abstract}
Systems coaching generally refers to coaching assorted groups of people, whether they entail corporate teams or families. However, systems are also present within individuals. Such systems, representing different value clusters, interact between coach and client, and sometimes present coaching challenges. A well-known category of these systems within individuals has been broadly defined as "typology," encompassing Jung's theory of psychological types, temperaments, and social styles (among others) in a tripartite view of individual psychology. In this paper, I present an outline of three well-known typological models and explain how the values they encompass play into coaching relationships. I discuss how an emergent system results from the interaction of these individual systems via the field that materializes between coach and client. I conclude with suggestions for ways coaches can utilize these typological models to reveal the values inherent in each client's psyche in order to enhance the effectiveness of the coaching process.
\end{abstract}

Keywords: typology, temperament, social styles, systems coaching

\section{Introduction}

Whenever one raises the topic of "systems coaching," it is generally presumed that one refers to systems of persons who are interacting in assorted groups, whether they involve organizational settings or within families or communities. Yet consideration must also be granted to the notion that individual humans are also systems within themselves. One of the oldest psychological traditions is the "tripartite division of human attitudes, or psychic functions: cognitive, conative, affective" (Jarrett, 1993, p. 20). This threefold classification originated in the German faculty psychology of the eighteenth century, although Brett (1921) claims to have found some earlier evidence for it in Aristotle and clear signs of it in Augustine, describing how "his language at times suggests the same threefold division into knowing, feeling, and willing" (p. 139).

These three psychological realms encompass a multitude of aspects contained within every human personality, and it requires little imagination to 
recognize how the value clusters expressed by each of these aspects greatly impacts the ways in which coaching relationships unfold. Without awareness of these different realms, values clashes may unintentionally occur and distort or disrupt the coaching. Since problems are doorways to every client's development, it is helpful to have access to a variety of models that provide data about what lies beyond the portal. Accordingly, brief snapshots of each of these modalities follow.

\section{The Three Divisions}

\section{Conative}

It is unfortunate that conative psychology is not better known in the coaching community since it impacts coaching so broadly. Conative psychology relates to "why" persons behave the way they do. It is the "personal, intentional, planful, deliberate, goal-oriented, or striving component of motivation" (Huitt, 1999, p. 1) that is commonly framed as a behavioral model since it postulates individual differences in behavior that can be explained by physiological mechanisms. A popular example of a conative approach to understanding human personality has been represented by temperament theory, which has an ancient history originating around 460 B.C. with Empodecles, who determined that the primary elements of the universe were earth, air, fire, and water. Around 430 B.C., Hippocrates deduced from them four "humours" that described various fluids in the body, and which Claudius Galen, some 250 years later, developed into the first typology of temperament, referring to the phlegmatic, melancholic, sanguine, and choleric types.

Since Hippocrates' and Galen's innovations, various reinterpretations of this model have been proposed by other theorists over 25 centuries, such as Paracelsus in the 16th century, who contributed the notion that human behavior was influenced by four kinds of "spirits" (nymphs, sylphs, gnomes, and salamanders). Anthropologists report that conceptions of different temperaments have existed around the world for thousands of years and parallels to this scheme have been identified in a variety of cultures, such as the four "Central Desires" characterized in Hindu teachings and the four "Spirit Keepers" represented by the Native American medicine wheel.

In more contemporary times, Eduard Spranger (1914), Ernst Kretschmer (1925), and William Sheldon (Sheldon, Stevens, \& Tucker, 1940) revived the notion of the four temperaments. They in turn inspired David Keirsey (1984) to 
create a modern interpretation of the Hippocrates-Galen conception in the 1970s. Keirsey claimed that "temperament is the pattern of instinctive communications" (Keirsey \& Hammer, 1983, p. 6). Building on Keirsey's work, his former student Linda Berens (2010) updated temperament theory in the early 21 st century and produced an over-arching meta-model that integrated temperament theory with other models in a multi-pronged approach.

The word temperament comes from the Latin temperare, as in temporary or temporal. It might be said that tempering is a kind of timing or synchronization of the whole, with all regions acting in unison. Despite its characterization as a behavioral model, the four temperament classifications are characterized by inner drives, including specific core needs, values, and talents that are often unconscious. Using Berens' terminology as an example:

- The Improviser temperament (correlating with Galen's sanguine) has a core need for "freedom to act on the needs of the moment," demonstrating values for "variety" and "skilled performance" (Berens, 2013, p. 9).

- The Stabilizer temperament (correlating with Galen's melancholic) has a core need for "membership; belonging; a place to contribute," demonstrating values for "security" and "continuity" (Berens, 2013, p. 9).

- The Theorist temperament (correlating with Galen's phlegmatic) has a core need for "knowledge and competence," demonstrating values for "progress" and "logical consistency" (Berens, 2013, p. 9).

- The Catalyst temperament (correlating with Galen's choleric) has a core need for "deep meaning and significance," demonstrating values for "authenticity" and "empathic relationships" (Berens, 2013, p. 9).

In a coaching context, recognizing the temperament of a client empowers the coach to frame powerful questions that are resonant with the client's values. Understanding the similarities and differences between the values of the various protagonists in traditional systems coaching helps the coach to perceive and grasp areas of conflict and accord. When core needs have gone unmet, or when values are not being honored, the resulting stress reactions are likely contributors to whatever issues are being presented by the client. Knowledge of temperament theory can help a coach to collaboratively formulate strategies that alleviate those stressors. 


\section{Affective}

Affective psychology claims to relate to the emotional basis of our behavior, especially in relationship with others, and ultimately seems to characterize a variety of native energy patterns that individuals exhibit. Also classed as a behavioral model, it originated in the 1920s when William Marston (1928/2015) developed a scheme that postulated different styles of behavior. Marston suggested that human beings adopt one of four styles in any relationship - they either display Dominance, Inducement, Submission, or Compliance. This gave rise to what he termed the "DISC" model (p. 105).

Marston's original terms were considered to be controversial, leading subsequent theorists to rework his conception. Eventually, three of Marston's terms were replaced, ultimately arriving at a new "DISC" (still embraced today) that now stands for Dominance, Influence, Steadiness, and Conscientiousness. The acronym "DiSC" (with a lower case "i") is a registered trademark of John Wiley \& Sons, who developed a popular assessment aimed at revealing individual preferences according to Marston's model (Scullard \& Baum, 2015).

In order to avoid the possibility of trademark infringement, Marston's scheme is often referred to generically as "social styles" by other theorists. Variations of the model include the "Platinum Rule" (Alessandra \& O'Connor, 1996), the "Thomas-Kilmann Conflict Styles" (Thomas, 2002), and "People Styles" (Bolton \& Bolton, 1996), among others. Berens (2008), as was mentioned previously, reworked the social styles model and removed some unfortunate conflations with the temperament domain in order to produce her own version, dubbed "Interaction Styles," employing terminology that integrated it seamlessly with models from the other two realms that are here discussed.

The four social styles are characterized by energy values that result from core drives and beliefs that are typically unconscious. Using Berens' terminology as an example:

- The In-Charge interaction style (correlating generally with the " $\mathrm{D}$ " in the DISC version) exhibits "determined" energy with a core drive of an "urgent need to accomplish in a timely manner" (Berens, 2013, p. 11).

- The Chart-the-Course interaction style (correlating generally with the "C" in the DISC version) exhibits "focused" energy with a core drive of a "pressing need to anticipate and have points of reference" (Berens, 2013, p. 11). 
- The Get-Things-Going interaction style (correlating generally with the "I" in the DISC version) exhibits "engaging" energy with a core drive of an "urgent need to involve others and be involved" (Berens, 2013, p. 11).

- The Behind-the-Scenes interaction style (correlating generally with the "S" in the DISC version) exhibits "calmly open" energy with a core drive of a "pressing need to integrate and consider many sources" (Berens, 2013, p. 11).

Within a coaching context, apprehending the energy values of a client's interaction style helps to overcome frustrations when this energy is being blocked due to environmental circumstances. While interacting with others, a difference in energy values as a result of incompatible interaction styles may lead to conflict. Understanding core drives allows a coach to flex and create rapport, and to establish alignment with the client's agenda when addressing the goals and challenges that clients are experiencing.

\section{Cognitive}

Cognitive psychology is a burgeoning field of contemporary study that has eclipsed the other two domains, much to psychology's detriment. One popular rendition is based on C.G. Jung's (1921/1976) well-known theory of psychological types, as described in his book of that name, published in 1923 (English version). In it, he postulated four mental functions of consciousness that are employed by every human psyche in everyday life. These functions are known as sensation, intuition, thinking, and feeling. Unlike the conative and affective models which are both characterized by fourfold schemes, Jung added an extra dimension to his model, indicating that each of these four functions is expressed in one of two attitudes - introversion or extraversion - thus comprising eight "function-attitudes" altogether. 
Figure 1: John Beebe's "semantic fields" for the eight cognitive processes.
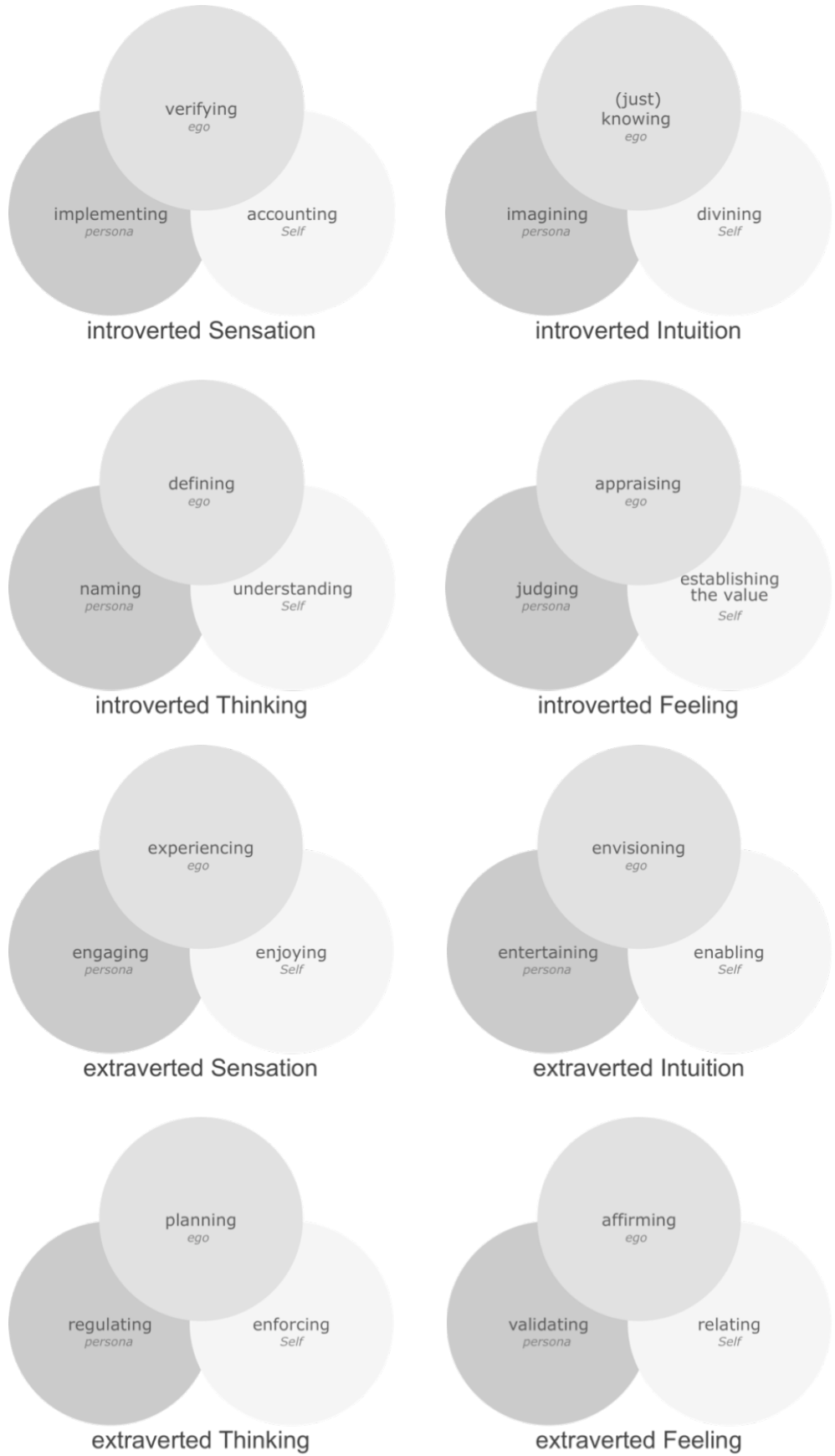
Jung proposed that these eight function-attitude pairs manifested in the human psyche in a preferential sequence, from most valued to least valued. He devoted an entire chapter of his seminal book to colorful descriptions of these mental processes, and subsequent authors have likewise expounded on the characteristics of each of them. For the sake of simplicity, I will précis them by using John Beebe's (2017) three-term gerunds for each process which, when combined, are intended to evoke the "field" of each form of consciousness as well as indicate a likely path of cognitive development (p. 17), as shown in Figure 1.

This mercurial aspect of Jung's model is less well known, and too often his scheme is portrayed as merely a positive psychology model that defines ego "strengths," while it is unfortunately overlooked that it also describes shortcomings (which is probably what the client is actually seeking help with in the coaching relationship). This popular model is likely to be more familiar to coaches than the others mentioned above, since " $49 \%$ of coaches report using the MBTI in their work" (Bennet, 2010, p. 21).

Like the models already described, Jung's theory of psychological types essentially posits a complex set of values associated with each of the eight mental processes that were listed above, and Jung (1970) himself explained how "our psyche actually possesses an extraordinarily well-developed evaluating system, namely the system of psychological values" (p. 9). It has been mapped to Gardner's (2011) model of "multiple intelligences" and evidences much of the same diversity. Unfortunately, Jung's psychological types are often reduced to labels and stereotypical traits and reductive behaviorism rather than viewed as a dynamic and cutting-edge model of consciousness, and it is commonly overlooked that Jung's model is distinctly psychic. As a result, scant attention is paid to the values that are inherent to each of these various forms of consciousness.

Although Jung declared that individuals have preferences for certain instances of the eight cognitive processes, everybody makes use of all eight at various times during a typical day as their circumstances warrant. Understanding which of these functions is being utilized at any point in time is valuable information for a coach when navigating a client's experiences, frustrations, and blind-spots. Mining around whether the function that is under discussion is more-valued or less-valued may significantly impact how a coaching session unfolds and contribute useful insights and breakthroughs. Furthermore, coaching often stimulates Jung's renowned "transcendent function" when evoking the greatly desired transformations that coaching 
clients and their coaches are typically aiming for. Too complex and technical to elucidate here, the transcendent function essentially catapults the client to a new, higher level of awareness than had been attained previously, and is the secret ingredient mysteriously operating behind the scenes throughout every successful coaching engagement.

\section{Others}

Many other approaches can be used to describe the functioning of the human psyche, ranging between behavioral psychology, neuroscience, archetypes, synchronicity, and dialogical development, to name only a few. Space does not permit the amplification of these myriad modalities.

An additional division might be contributed to this tripartite scheme to simply account for that which is "unknown." Soma, culture, psychological development and maturity (a domain where new models are being proposed and developed) might comprise a dim and mysterious fourth domain of influence not encapsulated in these first three domains.

\section{Discussion}

Each of these models describes separate, yet interrelated, systems operating in the human psyche that relate powerfully to each individual's hierarchy of values. While it is enormously insightful when working with clients to possess knowledge of these three different realms and to recognize the systems of values they represent within each person's psyche (and may require coaching around reconciling internal values conflicts, such as those evidenced by experiences of ambivalence), where they become heightened is with respect to another system - which is the "system" created between the coach and client when they begin working together.

This curious system that materializes between the two parties is at the cutting edge of personal development work, and comprises phenomena such as those being termed the "interactive field" and "emergence" (Cambray, 2011). In other words, when two individuals intersect and commingle, they become more than two systems operating independently in the space - a third system is generated dynamically between them, which is termed the interactive field, and this field reflects an interplay that is occurring between the original two systems. As the systems engage with one another and the interactive field is created, values, forms, and images emerge dynamically in the moment that may be experienced as either ego-compatible or ego-incompatible between the two 
individuals, probably due to a values match or mismatch. This mechanism or transaction lies at the core of every coaching engagement and informs the failure or success of the coaching encounter.

The interactive field shapes the coaching experience to such an extent that coaches are encouraged to define their "niche" and "ideal client" in order to predispose the interactive field favorably, often by narrowing the range of eligible clients to those who perhaps optimally mirror the values and preferences or tendencies of the coach. In terms of marketing, the coach may be advised to advertise a problem-solving "message" that is essentially some variation of "be like me" or "do what I did." This message may be offered from the comfort zone of an advice-giving standpoint rather than the coach operating as a pristine conduit who is capable of putting ego aside in order to engage with a client's unconscious so as to bring forth new possibilities for them. This is especially understandable since negative projections often arise within the interactive field and taint the relationship to a degree that the coaching becomes ineffectual for both parties.

Rather than limiting the diversity of a coach's clientele, paraphrasing the words of J. D. Frank (1974), we believe instead that a proficient coach "should master as many rationales and procedures as possible and try to select those that are most appropriate for different clients" (p. 271). Accordingly, wise coaches will familiarize themselves with different modalities of human personality so as to interface effectively with these variegated facets of their client's psyche, and strive to leverage a variety of models to serve the client's success. After all, these myriad value differences in psychological orientation between the coach and client impinge on the coaching experience whether they are consciously recognized or not. Human beings are complex creatures!

Coaches are rarely educated formally in the understanding and use of these frameworks as part of their official coach training. Instead, training in these paradigms is more likely to be undertaken by the coach based upon personal interest or recommendations from others, or be ported over from another career path, such as studies in psychology or positions in Human Resources departments. Situations may then arise where a coach becomes aligned with a model that only represents one of these three domains, which they may attempt to use with all coaching clients in all situations. Every coaching relationship they establish may end up forced into that singular Cinderella slipper, no matter how poorly it fits, with a lack of awareness that they are relying on an unsuitable model to address a client's issue. They may become mired in an unfortunate bias that betrays an over-reliance on a preferred 
tool, embodying the truism Abraham Maslow (1969) warned of, stating, "I suppose it is tempting, if the only tool you have is a hammer, to treat everything as if it were a nail" (p. 15).

This is not to suggest that a coach should immediately subject each client to a battery of assessments in order to determine which characteristics are preferred, but is rather advised to keep these models in the back of their mind and watch for clues as to which aspect of each model is presenting itself during the coaching session. For example, although I am qualified to administer the MBTI, and have been using it professionally for over 25 years, I characteristically avoid deploying any jargon related to that instrument since preconceptions about the meaning of the codes can adversely influence or even derail the progress of coaching. The same is true with the other models previously mentioned. However, I am continually referencing these models in background, so to speak, and forming my own private opinions about the psychological preferences that my client has in relation to each of them and appraising their values through these multiple interdependent lenses. This in turn allows me to tailor the coaching sessions to achieve the greatest efficacy and demonstrate a vested interest in the client's ongoing success.

\section{Conclusion}

Every coach confronts an elaborate ecosystem embedded in each client's psyche which presents multifaceted challenges for both of them. Typological models that describe the conative, affective, and cognitive domains of psychology assist everyone in a deeper understanding of these interconnected systems. They provide us with useful algorithms and roadmaps that furnish guidance and suggest navigational insights. Given the complexity and individuality that is manifested by every coaching client, it is unlikely that any single model on its own provides a comprehensive blueprint for coaching. However, the use of multiple models may help the coach grasp the varied landscape of a client's unique psychology.

Rather than superficially classifying individuals (and perhaps "pigeonholing" or "stereotyping" them) according to various traits and behaviors, these models congruently and effectively identify what values are important to the client, since each of them describes an implicit cluster of standards that interrelate (and sometimes disagree). These values provide compelling and effective indicators for coaches to work with. Coaches, coach supervisors, and coach educators/trainers are encouraged to learn and adopt the use of models of the psyche with a focus on using them to identify and navigate 
values above all. Building on that, the mindset of holding the coaching relationship as an emergent, interactive system stimulates greater collaboration and curiosity about what might elevate that co-constructed system to higher levels of effectiveness.

This paper outlined three models of typology that address separate domains of psychology with a recognition that many more exist that could not be addressed due to space constraints. All of these models may be employed to discover what values are significant to a client and may thus be pressed into service to help the resourceful coach better understand and appreciate the various complex systems at work within the client's enclosed psyche, and to discern as coaches how these systems inform our interactive field.

\section{References}

Alessandra, T. \& O'Connor, M. (1996). The platinum rule: Discover the four basic business personalities and how they can lead you to success. New York, NY: Grand Central Publishing.

Beebe, J. (2017). Energies and patterns in psychological type: The reservoir of consciousness. New York, NY: Routledge.

Bennet, A. (2010). The shadows of type. Morrisville, NC: lulu.com.

Berens, L. (2008). Understanding yourself and others: An introduction to Interaction Styles 2.0. West Hollywood, CA: Radiance House.

Berens, L. (2010). Understanding yourself and others: An introduction to the 4 temperaments-4.0. West Hollywood, CA: Radiance House.

Berens, L. (2013). A Meta-Model for Types - Patterns, Polarities, and Autopoesis. Integral Theory Conference, July 2013.

Bolton, R. \& Bolton, D. (1996). People styles and work: Making bad relationships good and good relationships better. New York, NY: Ridge Associates.

Brett, G. (1921). A history of psychology, medieval and early modern period (Volume 2). London, UK: George Allen and Unwin.

Cambray, J. (2011). Moments of complexity and enigmatic action: a Jungian view of the therapeutic field. Journal of Analytical Psychology, 56(3), 296-309. DOI: 10.1111/j.1468-5922.2011.01912

Frank, J. D. (1974). Psychotherapy, the Restoration of Morale. American Journal of Psychiatry, 131(3), 271-274. DOI: 10.1176/ajp.131.3.271

Gardner, H. (2011). Frames of mind: The theory of multiple intelligences. New York, NY: Basic Books. 
Huitt, W. (2006). Social cognition. Educational Psychology Interactive.

Valdosta, GA: Valdosta State University. Retrieved from http://www.edpsycinteractive.org/topics/soccog/soccog.html

Jarrett, J. (1993). The Place of Art in the Education of Feeling. Arts Education Policy Review, 95(2), 20-26.

Jung, C. G. (1970). The structure and dynamics of the psyche. (H. Read, M. Fordham, G. Adler, \& W. McGuire, Eds. R. F. C. Hull, Trans.). Princeton, NJ: Princeton University Press.

Jung, C. G. (1976). Psychological types. (H. Read, M. Fordham, G. Adler, \& W. McGuire, Eds., R. F. C. Hull, Trans.). Princeton, NJ: Princeton University Press. (Original work published 1921)

Keirsey, D. \& Brownsword, A. (1983). Temperament Theory and the Theory of Functions. MBTI News: Newsletter of the Association for Psychological Type, 6(1), 5-9.

Keirsey, D. (1984). Please understand me: Character and temperament types. Del Mar, CA: Prometheus Nemesis Book Company.

Kretschmer, E. (1925). Physique and character. (W. J. H. Sprott, Trans.). New York, NY: Harcourt, Brace \& Company, Inc.

Marston, W. (2015). Emotions of normal people. New York, NY: Harcourt, Brace and Company. (Original work published 1928)

Maslow, A. (1969). Psychology of science: A reconnaissance. Washington, DC: Gateway Editions.

Myers, I., \& McCaulley, M. (1985). Manual: A guide to the development and use of the Myers-Briggs Type Indicator. Palo Alto, CA: Consulting Psychologists Press.

Scullard, M. \& Baum, D. (2015). Everything DiSC manual 1st edition. Hoboken, NJ: John Wiley \& Sons, Inc.

Shamdasani, S. (2003). Jung and the making of modern psychology: The dream of a science. Cambridge, UK: Cambridge University Press.

Sheldon, W. H., Stevens, S. S., \& Tucker, W. B. (1940). The varieties of human physique. Oxford, UK: Harper.

Spranger, E. (1914). Types of men. (P. J. W. Pigors, Trans.). Saale, Germany: G. E. Stechert Company.

Stelmack, R. \& Stalikas, A. (1991). Galen and the Humour Theory of Temperament. Personality Individual Differences, 12(3), 255-263.

Thomas, K. (2002). Thomas-Kilmann conflict mode instrument. Palo Alto, CA: Consulting Psychologists Press. 


\section{Acknowledgements}

"DiSC" is a registered trademark of John Wiley and Sons in the United States and other countries.

"MBTI" and "Myers-Briggs Type Indicator" are trademarks or registered trademarks of The Myers \& Briggs Foundation in the United States and other countries.

\section{Author Contact}

The author can be contacted via her website: vjvphd.com 